\title{
Reflexões Ético-Políticas de Questões Metodológicas de Pesquisa em Psicologia: Problema e Objetivos
}

\author{
Ethical-Political Reflections on Methodological Issues of Research in Psychology: \\ Problem and Objectives
}

\section{Reflexiones Ético-Políticas sobre Cuestiones Metodológicas de la Investigación en Psicología: Problema y Objetivos}

\author{
Anita Guazzelli Bernardes ${ }^{1}$ \\ Universidade Católica Dom Bosco (UCDB)
}

\author{
Neuza Maria de Fátima Guareschi \\ Giovana Barbieri Galeano
}

Universidade Federal do Rio Grande do Sul (UFRGS)

\begin{abstract}
Resumo
Este texto pretende refletir sobre objetivos e problema de pesquisa a partir de uma dimensão ético-política, por meio de uma perspectiva da Psicologia Social crítica. Partimos de um exercício de problematização que compreende o problema e objetivos de pesquisa como práticas situadas. Assim, apontam-se alguns elementos importantes desse exercício de pensamento - formulação de objetivos e problemas - a partir da experiência e de barreiras que devem ser consideradas. A experiência e as barreiras aparecem no texto como estratégias para afirmar a pesquisa como aposta ético-política. A ideia é refletir como essas dimensões éticas e políticas são coextensivas ao problema e aos objetivos da pesquisa também, afirmando, assim, o caráter situado, portanto, as implicações de todos os movimentos que realizamos durante os processos de investigação.
\end{abstract}

Palavras-chave: objetivos, problema, Psicologia Social, ética, política

\begin{abstract}
This text aims to reflect on research objectives and problems from an ethical-political dimension, from the perspective of critical social psychology. We depart from a problematization exercise that understands the problem and research objectives as situated practices. Thus, some important elements of this thinking exercise - formulation of objectives and problems - are pointed out from experience and the barriers that should be considered. Experience and barriers appear in the text as strategies to affirm research as an ethical-political bet. The idea is to reflect how these ethical and political dimensions are coextensive to the problem and the objectives of the research as well, thereby affirming the situated character, thus, the implications of all the movements we carry out during the research processes
\end{abstract}

Keywords: objective, problem, Social Psychology, ethics, politics

\section{Resumen}

Este texto se basa en la discusión sobre los objetivos y problema de la investigación a partir de una dimensión ético-política, desde una perspectiva de Psicología Social crítica. Partimos de un ejercicio de problematización que entiende el problema y los objetivos de la investigación como prácticas situadas. Por lo tanto, se señalan algunos elementos importantes de este ejercicio de pensamiento - formulación de objetivos y problemas - desde la experiencia y las barreras que deben ser consideradas. La experiencia y las barreras aparecen en el texto como estrategias para afirmar la investigación como una apuesta ético-política. Se trata de reflexionar cómo estas dimensiones éticas y políticas son coexistentes al problema y a los objetivos de la investigación, afirmando así el carácter situado, por lo tanto, las implicaciones de todos los movimientos que llevamos a cabo durante los procesos de investigación.

Palabras clave: objetivos, problema, Psicología Social, ética, política

\footnotetext{
${ }^{1}$ Endereço para contato: Universidade Católica Dom Bosco - Mestrado e Doutorado em Psicologia - Av. Tamandaré, 6.000, Jd. Seminário, Campo Grande, MS, Bloco M. CEP: 79117-900. Telefone: (67) 3312-3605. E-mail: anitabernardes1909@gmail.com
} 


\section{Introdução}

Este texto tem como foco refletir sobre a formulação dos objetivos e do problema de pesquisa implicados com a realidade que os torna possíveis. Parte-se, assim, de um exercício de problematização em que se considerará que o problema e os objetivos de pesquisa são práticas situadas, na medida em que não existem por si mesmos, mas em razão de um conjunto heterogêneo de práticas e saberes. Para isso, utilizaremos dois disparadores na discussão: teoria e experiência (Deleuze \& Foucault, 1972/1979; Foucault, 2003). O texto se apoia em uma perspectiva da Ontologia do Presente, que constitui uma Psicologia Social crítica, organizada pela intersecção de autores pós-estruturalistas, pós-coloniais, decoloniais e alguns estudos feministas.

Esta discussão se volta para o processo de produção do problema e dos objetivos de pesquisa que cria certas necessidades de problematização, assim como o trabalho feito sobre procedimentos metodológicos e implicações epistemológicas. Essas problematizações se referem, entre outras, à forma como os objetivos e o problema de pesquisa devem ser considerados enquanto dimensões relevantes em termos éticos e políticos, assim como à definição de métodos/teorias/resultados. Não se trata de uma questão atual ou inédita, porém a ênfase sobre as questões éticas e políticas se volta com maior frequência para as dimensões teóricas e metodológicas. Essas considerações são feitas a partir de um rastreio na Biblioteca Virtual de Saúde (BVS) e SciElo, em que, nos últimos cinco anos (2015-2019), encontram-se poucas publicações que discutam sobre essa temática, pois, conforme escrito, as problematizações tendem para os aspectos epistemológicos e metodológicos.

A proposta se apoia na perspectiva de colocar em análise problema e objetivos, no sentido de indicar um procedimento de pensamento mais "densificado", e não simplesmente um ato burocrático que desaparece nos percursos de investigação. $\mathrm{O}$ ato burocrático se refere à forma como o problema e os objetivos de pesquisa são posicionados em termos de etapas da investigação, e não propriamente como dimensões de formas de produção de uma pesquisa, que implica, também, processos de reflexão constituídos pela relação com a temática a ser investigada. A densificação, nesse caso, seria um procedimento de complexificação dos processos de pensamento. Isso envolve todo o ato de pesquisar, e não apenas as partes que o compõem, na medida que se considera que o pensamento é um acontecimento, ou seja, um trabalho permanente de interrogação sobre aquilo que se sabe. Portanto implica um conjunto de articulações, conexões, capilarizações que torcem e tensionam, permanentemente, as investigações, recaindo sobre as maneiras de colocar e recolocar problemas e objetivos de pesquisa. A densificação se faz pela própria compreensão de que tanto os objetivos quanto o problema de pesquisa são também procedimentos de investigação que se modificam nos itinerários de pesquisa a partir dos diferentes encontros com as temáticas em termos empíricos, metodológicos e epistemológicos.

A proposta é justamente considerar objetivos e problema de pesquisa como ferramentas que tornam um pensamento possível e que constituem uma trajetória singular do ato de pesquisar. Isso implica deslocar objetivo/problema de um procedimento de formalização da pesquisa para procedimentos de provocações, interrogações, encontros, percursos, que permitem pensar diferentemente do que se pensa. Conforme escrito anteriormente, a discussão, neste texto, refere-se à reflexão sobre diferentes planos de composição das formas 
de investigação. Haveria, nesse caso, uma organização da ciência psicológica a partir de dois vetores: um que compõe um plano da analítica da verdade ou ciências da prova; outro que constitui uma ontologia do presente ou uma ciência dos indícios (Kastrup, 2007; Stengers, 2000). Este texto se orienta por um plano de composições da ontologia do presente.

Esse exercício se apresenta como aposta em uma política de pesquisa que se afirma em um jogo complexo entre os campos social, epistemológico, político e ético. Isso é colocado porque o texto se apoia em uma perspectiva crítica em Psicologia Social e, de forma mais ampla, nos modos de produção de conhecimento que se tecem na modernidade (mecanicista e positivista) e dos quais ainda somos herdeiros. A herança dessas maneiras de pesquisar se anuncia e denuncia-se, entre outros elementos, nas formas como se opera com objetivos e problema de pesquisa, ou seja, como a pesquisa acaba por absorver uma racionalidade mecanicista/positivista que esquadrinha o ato de pesquisar por meio de operações que formalizam a investigação em "etapas" sem, necessariamente, correlações entre si, na medida em que o pensamento opera de modo fragmentado, por partes separadas em órgãos e funções, sendo a finalização uma junção das partes, borrando a maneira como foram aproximadas. Essa operação implica, também, que certas "etapas" se tornem menos problematizadas ou apenas elementos formais para configurar uma pesquisa científica. Vejam-se os destaques atribuídos aos resultados das investigações, cujo peso costuma sobressair às mudanças de rotas demandadas pelo contexto estudado, uma vez que os resultados seriam mais importantes para o planejamento e a efetivação de práticas resolutivas/solução de problemas.

A questão primeira, aqui, é considerar a pesquisa como um corpo articulado que toma forma pelas conexões que se fazem possíveis de maneira situada, localizada. Trata-se de um corpo que não preexiste, mas que acontece em razão dos planos de composição que emergem à medida que a investigação se faz. Dito de outro modo, argumentamos que é a rede constituída entre os campos epistemológico, político, ético e social que demanda e cria as condições para a existência da pesquisa.

A outra questão a se pensar, e da qual também a proposta se distancia, é a daquele exercício que muitas pesquisas e pareceres apresentam de jogar com certos verbos para indicar os objetivos e o problema, como se eles não tivessem impactos nas trajetórias efetivas das investigações, isto é, acabam por se exibirem como um jogo de não repetição gramatical (analisar, descrever, problematizar, apontar, indicar, comprovar etc.). Esse jogo de não repetição gramatical se faz porque se tomam os verbos como representações, e não propriamente como produções de mundo. Em razão disso, a ação do verbo no mundo, mais especificamente na pesquisa, não assumiria sua força ilocutória, apenas representaria perspectivas; portanto não haveria uma problematização das implicações dos verbos que organizam os objetivos e problemas, eles seriam apenas nomeações de atos, sem considerar os efeitos desses atos no mundo e sua relação com a perspectiva epistemológica e metodológica a partir dos quais se apresentam. Ademais, na língua portuguesa, os verbos no infinitivo implicam a definição de uma ação sem a informação de número, pessoa ou tempo, o que denota não apenas uma ideia de neutralidade, da qual também nos distanciamos, mas, precisamente, uma não historicidade e perpetuação de uma ação.

Em razão disso, refletir sobre problema e objetivo é fazer gaguejar certos elementos das pesquisas que, muitas vezes, perdem sua potência quando a finalidade da investigação se torna meramente a comprovação daquilo que já se sabe; ou a comprovação de um mundo 
que apenas precisaria ser representado pela ciência; ou a comprovação da não implicação da ciência com o modo como vivemos e habitamos o mundo. A expressão gaguejar é utilizada por Stengers (2000) para se referir à instabilidade das certezas que desestabilizam as pesquisas e permitem que reorientem as coordenadas, os itinerários pensados inicialmente. Problematizar essas questões, no sentido de se afastar delas, implica um procedimento de crítica permanente sobre o próprio ato de pesquisar e o que, com isso, produz-se de mundos e formas de habitar o mundo.

Nesta escrita, portanto, em um primeiro momento, são discutidas questões sobre teoria e experiência para amarrá-las aos objetivos e problema de pesquisa; a partir disso, consideram-se as implicações políticas e éticas que envolvem a formulação de objetivos e problema de pesquisa; dessas questões - teoria, experiência, ética e política -, parte-se para a discussão sobre problema e objetivos a partir da noção de pesquisa situada.

\section{Questões sobre Teoria e Experiência}

Dois textos, em um primeiro momento, auxiliam como disparadores da discussão: "Os intelectuais e o poder" (Deleuze \& Foucault, 1972/1979) e "Cómo nace un libro-experiencia" (Foucault, 2003). São disparadores, porque ambos colocam duas questões fundamentais para uma discussão sobre objetivos e problema em pesquisa: teoria e experiência.

O primeiro texto apresenta uma reflexão em que as teorias são tomadas como caixas de ferramentas e, além disso, toda teoria encontra metaforicamente um muro, na medida em que é sempre localizada e situada, ou seja, não é passível de universalização ao se considerar as condições políticas, epistemológicas, geográficas e históricas que a permitem ser formulada em termos de regime de verdade. O muro se faz justamente pelo campo social ou, como escrito no texto, pelas diferentes práticas com as quais as teorias se encontram e esbarram, em termos de limites e desafios que interrogam as verdades que produz. Nesse caso, a teoria sai de um nível de representação de mundo para se tornar ação no mundo, já que existe um ato de se encontrar com algo que difere dela mesma. A teoria, assim, torna-se ela própria uma prática que deve se conformar como sistema regional de luta, uma vez que age em um mundo que age sobre ela mesma: encontra-se com um muro e atravessa o muro, de modo que a "teoria não totaliza; a teoria se multiplica e multiplica" (Deleuze \& Foucault, 1972, p. 71). Primeira pista, então: teoria não é apenas um conjunto de conceitos que explicam o mundo; teoria é um sistema estratégico em um campo de lutas que se multiplica e faz multiplicar.

Essa primeira pista se torna importante, porque considerar a teoria como um sistema estratégico de luta, de não totalização, mas de multiplicação, significa situá-la como uma ação no mundo, e não fora dele. A teoria se faz em um mundo e opera nesse mundo, de forma que é com o mundo que a teoria conversa, encontra-se, articula-se. Isso implica que um conhecimento que se produz a partir de um campo teórico é sempre situado; portanto, os objetivos e o problema de pesquisa, como operações em um campo teórico, passam também a ser situados e localizados em razão das condições que se produzem ao se atravessarem os muros e das lutas que fazem o mundo se multiplicar.

Aqui a luta é considerada pelo jogo que se estabelece em termos de produção de verdades e subjetividades. Como jogo, a teoria também se conforma por meio de relações 
de poder; a teoria é uma formalização de relações de força, um modo de estabilização das forças em termos de sentidos, formas de poder afetar e ser afetado. A teoria não comporta nenhuma "ingenuidade" em relação ao mundo do qual faz parte; pelo contrário, é nesse mundo que se faz possível e é nesse mundo que se agenciam possibilidades. Dessa forma, os objetivos e o problema de pesquisa compõem ainda um campo de lutas, de relações estratégicas, tanto no pensamento quanto naquilo que produzirão em termos de possibilidades no mundo, também não se configurando como "ingenuidades". O processo de formalização de objetivos e problema de pesquisa é, em si mesmo, efeito de relações de força, de afetar e ser afetado, mas também de resistir e insistir.

No segundo texto, "Cómo nace un libro-experiencia" (Foucault, 2003), Michel Foucault considera que se pensa mais como um experimentador do que como um teórico, pois aquilo que escreve permitiria atravessar uma experiência de modo a modificá-la. Sendo assim, cada novo projeto alteraria os conceitos alcançados anteriormente, ao mesmo tempo em que permitiria uma mudança em si mesmo e no que se pensava anteriormente. $O$ autor acrescenta a isso certas heranças que carrega de Nietzsche, Blanchot, Bataille e Klossowski, que não se ocuparam de construir sistemas, mas de atravessar experiências diretas, singulares. Trata-se de uma experiência de "desgarrar" o sujeito de si mesmo para se tornar outro. Esse texto situa um projeto, uma escrita, uma investigação no âmbito da vida, da experiência e das possibilidades de se tornar outro. A experiência é tanto ponto de partida quanto aquilo que se modifica. A experiência permitiria sair dela transformado e também transformar e criar novas relações com o que se produz como conhecimento, temas, objetos.

Aqui, então, apareceria uma segunda pista para pensar sobre objetivos e problema de pesquisa, uma vez que permite considerar que a investigação é um processo que se forja no âmbito da experiência; portanto, como escreve Machado (2014, p. 5), “. . . o conhecimento é um acontecimento empírico” para ultrapassar experiências e constituir novas relações e subjetivações. A experiência se faz tanto como solo do qual se parte, novamente acentuando o caráter situado do conhecimento, quanto das possibilidades de transformar essa mesma experiência localizada. Isso implica considerar que objetivos e problema são emergências de uma experiência direta, singular, porém não em um sentido internalista, individualista, mas no sentido de um modo de articulação com um tempo, com um lugar. Isso porque, a partir da experiência, como estratégia de produção de conhecimento, engendra-se uma possibilidade de transformação da relação com algo que é datado e localizado, portanto, coletivo.

Essas duas questões - teoria e experiência - são condições de possibilidade para um pensamento que se interroga, não por uma dúvida cartesiana, mas por um campo de lutas, de relações de forças que formalizam o tensionamento do pensamento em um ato de pesquisar, tornando a própria inspiração de um pensamento, uma prática. A tensão que se produz, então, na relação entre um campo teórico e uma experiência (que também comporta a dimensão teórica) abre espaço para localizarmos objetivos e problema de pesquisa, bem como para operá-los como atos, como práticas para ultrapassarmos aquilo que somos ou nos tornamos. Ou seja, não há experiência sem um campo teórico que a torne percebida, assim como não há um campo teórico que não parta de um domínio de experiências que o fazem tomar certos contornos e não outros. Isso porque a experiência é um conjunto heterogêneo de sensibilidades ativadas por dimensões empíricas e ao mesmo tempo conceituais, quando nos afetam de certos modos e não de outros; a teoria é um campo de ações circunscritos, 
portanto, também experiências organizadas por certas curvaturas conceituais. Assim, não há uma experiência completamente destituída de alguns registros conceituais que permitem nossa localização nessa experiência, assim como não há teoria que não seja provocada por experiências que a tornam possível de ser formulada. A relação não é de causa-efeito, mas de reciprocidade que tensiona. A tensão se faz justamente porque não se trata de uma relação de encaixe de peças, mas de composições que negociam as formas de articulação.

Aqui podemos pensar também como a experiência politiza a pesquisa. Bondía (2002) define a experiência como aquilo que nos acontece, que nos afeta em termos de fenômenos com os quais nos encontramos no mundo em que vivemos. Assim, a ciência tanto se torna possível porque está em um mundo que a afeta e que é condição de possibilidade para aquilo que formula como verdade, como também passa a ser considerada como uma forma de produção de experiências, de modo a ampliar a ideia de que ciência apenas produziria informações e explicações sobre o mundo. Isso significa compreender que as informações formuladas pela pesquisa não são espelhos do mundo. As informações são formas de performar o mundo e ser, ao mesmo tempo, efeito desse mundo. Assim, para que a pesquisa se corporalize como uma experiência, como diz Foucault (2003), é preciso que ela nos toque ou, como afirma Bondía (2002), que nos faça parar, escutar e pensar mais devagar ou suspender a opinião, o juízo, por alguns momentos, para evitarmos o automatismo do pensamento e das ações.

Para compreender que a pesquisa se corporaliza como uma experiência, é importante ter claro que o corpo do pesquisador está implicado no processo de produção de conhecimento. O corpo, ao qual nos referimos aqui, comporta as dimensões sensíveis que nos fazem sentir, pensar e perceber-nos em uma rede articulada de relações com aquilo que consideramos exterior a nós mesmos. Trata-se de um corpo que se constitui por aquilo que o afeta, de modo a localizá-lo no mundo e no modo de habitá-lo.

A tríade pesquisador, experiência e corpo é o modo de politizar a pesquisa ou de fazer com que sempre se tenha uma postura ético-política. A perspectiva de política, nessa discussão, é herdeira das considerações foucaultianas sobre o conceito. Dessa forma, quando se opera com o conceito de política, afirma-se uma perspectiva de ações sobre outras ações que produzem mundos e sujeitos, ou seja, são modos de governo das condutas que regulam as relações entre subjetividade e verdade. A ética aparece, assim, como um elemento que toma essas formas de regulação como normas facultativas, que devem considerar não a ação em si mesma, mas o efeito da ação sobre outras ações possíveis.

\section{Apostas Políticas e Éticas}

Para situar problema e objetivos de pesquisa nessas articulações entre teoria e experiência, é necessário que algumas perguntas sejam realizadas, a partir do momento em que se pensa em um tema ou na construção de um campo problemático para a pesquisa. As perguntas são: onde, como, por que e por quem o tema de pesquisa se torna problemático. Tentando responder a essas perguntas, colocamos em ação um exercício de pensamento da não naturalização sobre o conhecimento, tomando-o como situado e historicamente localizado, ou seja, pensamos sobre como e em que momento determinados saberes, ou posições teóricas e epistemológicas, passaram a considerar o tema de pesquisa problemático. 
A continuidade desse exercício de pensamento sobre o que torna um tema de pesquisa problemático é fundamental para a construção do problema e dos objetivos da investigação, pois isso também nos leva a refletir acerca das estratégias, tecnologias ou políticas que os saberes produzem, na tentativa de resolução dos possíveis efeitos oriundos do fato de o tema ter se constituído como um problema. Ainda nessa perspectiva de buscar um caráter mais arquegenealógico no exercício do pensamento, certamente nos deparamos com os saberes que se colocam como competentes, ou com autoridade e direito de falar, orientar ou dar as soluções para as demandas constituídas como problemas. A arquegenealogia é uma perspectiva metodológica que se ocupa de problematizar a formação de saberes (arqueologia dos diferentes regimes de verdade que se formam em um determinado tempo-espaço, considerados como estratos, camadas sedimentadas), bem como as relações de poder (genealogia das formas de governo das condutas).

Assim, ao realizarmos esse caminho para a construção do problema e dos objetivos de pesquisa, provavelmente, não correremos o risco de que eles contemplem, no conhecimento que buscaremos desenvolver ao longo do processo de investigação, somente a constituição do campo problemático que possibilitou que fossem elaborados, nem de que deixem de considerar, principalmente, a produção de práticas sociais que passam a construir modos de vida em determinados contextos e populações. Isso implica afirmar que a pesquisa não é isenta de uma postura ético-política, pois, à medida que o problema e os objetivos problematizam os próprios saberes que os construíram, visibilizamos a forma como esses saberes produzem sujeitos e seus efeitos nos modos de subjetivação. A experiência, tal qual escrevemos anteriormente, no caso de considerarmos a pesquisa dentro de uma dimensão ético-política, é uma forma de produção de subjetividade do próprio sujeito que pesquisa, em que o corpo entra em relação com outros corpos, em razão de um processo que é social, coletivo - ". . . não é a afirmação do sujeito na continuidade fundadora de seu projeto . . . É isso a experiência, é arriscar não ser mais si mesmo" (Foucault, 2018, p. 29).

A constituição de um problema e objetivos de pesquisa requer, necessariamente, caminhar por um campo temático no qual certos elementos aparecem e se organizam, indicando conexões entre elementos heterogêneos, como também controvérsias e paradoxos, que movimentam os modos como pensamos e nos articulamos com aquilo que pesquisamos. As articulações/conexões criam um plano extensivo e intensivo para a formulação de um problema e objetivos da pesquisa, apontando para um campo de relações e sensibilidades que nos situam no mundo - não no nosso mundo como pesquisadores e pesquisadoras, mas no mundo que compartilhamos com os outros e que nos interroga sistematicamente para arriscarmos a deixar de ser o que somos para nos tornarmos outros. Essa é a postura ética e política que agencia a forma como formulamos problema e objetivos de pesquisa.

Perguntas iniciais permitem acompanhar certos trajetos percorridos por uma temática dentro de um plano que envolve saberes e tecnologias que justamente a fazem aparecer. As perguntas apresentadas de modo a situar uma temática como acontecimento orientam a pesquisa a seguir os rastros deixados pelos elementos teóricos, metodológicos e/ou político-sociais que, de alguma maneira, ocupam-se da temática. São questões que começam a nortear o exercício de investigação a partir das condições de emergência e atualidade de um determinado fenômeno social. Questões como as indicadas anteriormente - onde, 
como, por que e por quem - auxiliam o pesquisador a se situar em um campo temático, mas, sobretudo, a iniciar o que se nomeia de problematização de um campo.

Trata-se de um rastreio com perguntas que permitem ensaios com o campo temático e as condições de visibilidade que começa a apresentar. Isso implica amalgamar teoria e experiência como um plano possível de produção de um problema de pesquisa e de seus objetivos a partir de certas estratégias de pensamento, de forma que as questões sejam efetivamente tomadas como estratégias que orientam os itinerários de pesquisa. As questões fazem parte de um processo de qualificação de um problema de pesquisa, e os objetivos se tornam seus correlatos.

A perspectiva de encontro entre teoria e experiência, a partir de rastreios em um campo guiado por algumas interrogações estratégicas, indica que os objetivos e o problema passam a ser pensados como atos de produção e, portanto, de invenção. Os objetivos e o problema, quando situados na relação com teoria e experiência, tornam-se possibilidades de formar conceitos como maneiras de viver, como conduções de conduta na relação que se estabelece com a verdade, ou seja, como substâncias éticas e políticas de uma trajetória de pesquisa. São estratégias de governo da conduta não como forma de aprisionar o ato de pesquisar, mas de situá-lo, de tensioná-lo, de provocá-lo a sair de si mesmo, na medida em que afetam (pois possuem regras, códigos que prescrevem como fazer, o que fazer), mas também são afetadas a partir das respostas e dos efeitos daquilo mesmo que produzem. Nesse sentido, os objetivos e o problema se constituem como indicadores epistemológicos (como se pensa) e indicadores críticos (como se interroga e reduções a serem evitadas). Trata-se, portanto, de estratégias que singularizam o ato de pesquisar e indicam as apostas políticas da produção de conhecimento. Apostas políticas, conforme escrito anteriormente: ações que produzem mundos/subjetividades e que devem considerar, justamente, que mundos e subjetividades estão sendo constituídos.

Essas pistas apontam que os objetivos e o problema de pesquisa se conformam como políticas, como posicionamentos implicados no modo de produção de mundo, nas formas de viver. Os objetivos e o problema indicam, assim, uma política de pensamento, uma política da vida, porque são ações no mundo. Isso significa que as escolhas "verbais", "gramaticais", indicam as apostas políticas: o que se quer, como se quer, o que se produz. Essas interrogações servem para o próprio pesquisador se implicar no ato de pesquisar. Ou seja, na montagem de um problema de pesquisa, há uma dupla vetorização que apoiará os objetivos da investigação: por um lado, trata-se de se voltar para um campo de exterioridade e seguir os rastros que tornam esse campo uma temática de pesquisa e aquilo que, sob certas condições, se faz visível e enunciável; por outro, inflexionar esse campo de exterioridade como um plano que interroga as escolhas, apostas, implicações do próprio pesquisador com certas formas de pesquisar. Isso significa que temos que saber o que perguntamos em termos de implicações epistemológicas, éticas e políticas.

Ter os objetivos de analisar, descrever, problematizar, apresentar, mapear, entre outros, como também perguntar o que é, de que modo, por que, sob quais condições etc., são procedimentos de pensamento feito por articulações conceituais e práticas, assinalando os posicionamentos e riscos de um ato de pesquisar. Essa proliferação gramatical para apresentar a finalidade da pesquisa e o fio condutor da investigação (tal qual é explicada nos 
manuais de metodologia científica), conforme escrito anteriormente, fala mais do pesquisador do que propriamente do que será feito. Fala mais do pesquisador porque indica, justamente, os regimes de verdade segundo os quais ele se conduz. Em se tratando de regimes de verdade, há, então, tanto um ato de constituição de si como pesquisador quanto um ato de condução de condutas pela pesquisa, o que nos situa em uma postura ético-política.

\section{Pesquisa Situada}

Ao localizarmos os objetivos e o problema de pesquisa no âmbito da experiência, especialmente nos jogos e nas tensões em que se encontram, apontamos a necessidade de considerar o conhecimento e as formas de produção de conhecimento de modo situado, como indicou Haraway (1995), quando discutia sobre a objetividade da ciência, e também outros autores que seguem nessa linha, como Grosfoguel (2016), Lowy (2008) e Mbembe (2016), entre outros, indicando a dimensão colonial do próprio pensamento. A problematização coIonial do pensamento foi posta em análise, sobretudo, por autores e autoras que se ocupam de pensar a relação entre conhecimento e formas de colonização, partindo de questões relacionadas à raça, ao gênero, à etnia. De diferentes modos, essas análises situam a ciência como parte de um conjunto estratégico de governo das condutas que produz genocídios, epistemicídios e etnocídios. Essas discussões colocam em análise os universalismos da ciência também como modo de colonização das vidas. Situam-se em campos que se autointitulam decoloniais (América Latina), anticoloniais (África e Ásia) ou mesmo pós-coloniais (teorias feministas, pós-estruturalistas ocidentais). A inspiração nessas reflexões nos auxilia a direcionar a discussão para as implicações daquilo que definimos como objetivo de pesquisa e os modos de perguntar que engendram os itinerários das investigações. Novamente, como escrito na introdução, trata-se de um exercício de "densificar" a pesquisa, tomando-a de forma localizada. Sinalizam-se, desde o princípio dos processos de investigação, certas heranças que colonizam a pesquisa e as próprias temáticas pesquisadas, conforme dito anteriormente sobre a necessidade de percorrer o campo de emergência de objetos em termos de saberes e tecnologias que passam dele a se ocupar.

De forma quase evidente, para não dizer ingênua, o objetivo de uma pesquisa se refere ao que se quer com ela, ou seja, onde se quer chegar e o que se quer com isso. O que se quer com uma pesquisa não se refere apenas à sua relevância ou originalidade, mas, sobretudo, à finalidade de pesquisar certos eventos, fatos, realidades no nosso presente. Considerar isso permite fazer certa torção nos verbos analisar, mapear, descrever, apontar, compreender etc., no sentido de que cada um deles traz uma forma como nos situamos como pesquisadores e aquilo que produzimos e podemos produzir com nossas pesquisas. Os jogos verbais são jogos políticos e éticos de investimentos no mundo que produzem experiências; então, devemos nos perguntar sobre aquilo mesmo que temos como objetivos de pesquisa, não no sentido utilitarista de "para que serve", mas no sentido performático de "o que produz" - o que faço com a pesquisa e os efeitos nos modos de pensar e viver. Essa questão sobre o sentido performático do que se produz se engendra, atualmente, no que tem sido considerado como modo de "prestação de contas" da ciência, ou seja, a responsabilidade por aquilo que a própria ciência produz, de modo a considerar seus efeitos no mundo (Rouse, 2007; Galison \& Stump, 1996). 
Atualmente, em razão das diferentes formas de regulação da pesquisa, especialmente pelas agências que financiam os projetos, há a necessidade de que os estudos apontem os impactos e as contribuições para a sociedade do ponto de vista social, econômico e ambiental. Além disso, com a presença cada vez maior de discussões críticas, no âmbito acadêmico, sobre a relação entre pesquisa e sociedade, há também uma indicação da importância de as investigações se articularem com o campo social, e não apenas "falarem" sobre o campo social. Isso pode ser considerado nos últimos anos a partir de diferentes manifestações acadêmicas em termos de respostas aos modos de regulação e de investimento no ensino e na pesquisa no Brasil; por exemplo, a Sociedade Brasileira para o Progresso da Ciência (SBPC) e a Associação Nacional de Pesquisa e Pós-Graduação em Psicologia (ANPEPP). Tanto na regulação pelas agências (os direcionamentos dos investimentos ou cortes de investimentos) quanto nas críticas dos modos de fazer ciência (o não reconhecimento da ciência no cotidiano, ou a consideração de que a ciência se faz em laboratório), entre outras formas de controle que vão se fazendo nesses percursos e na conexão com mercado, direitos humanos, movimentos sociais, pobreza, entre outros, há um plano mediante o qual a pesquisa começa a assumir uma dimensão mais "perigosa". O perigo reside tanto nos diferentes desafios atuais para se fazer pesquisa no País quanto no que diz respeito ao que a pesquisa produz, ou seja, é um desafio tanto para quem trabalha com pesquisa quanto para quem a financia e a regula.

Grosfoguel (2016) denuncia um movimento de epistemicídio acadêmico que ocorre em razão de racismo/sexismo acadêmicos. O autor percorre diferentes formas que silenciaram ou invisibilizaram certos modos de conhecer e produzir conhecimento, acentuando uma colonialidade do pensamento, e não apenas uma colonização dos espaços, o que, deslocado para a nossa discussão, tornou a formulação de problemas e objetivos de pesquisa um suposto ato "asséptico", em que a pesquisa seria uma metafísica da verdade descolada da política. Isso é possível considerar quando nos voltamos, inclusive neste próprio texto, para articulações com autores/autoridades acadêmicos fundamentalmente eurocêntricos ou estadunidenses. Nesse caso, não se trata de abdicar de certos campos teóricos, autores e campos temáticos aos quais nos filiamos, mas de situá-los em relação ao modo como constituem mundos e formas de pesquisar, ou seja, também são formas de governo e de governar.

A colonialidade do pensamento e os epistemicídios que ela engendra aparecem nas formas de pesquisar e se anunciam nos modos como estabelecemos os objetivos e o problema de pesquisa. A colonialidade residiria nesses deslocamentos/aclimatações de coordenadas de pensamento/problemas que acabam por capturar elementos que a colocariam em análise, que a interrogariam. Explica-se: a colonialidade agencia modos de condução da investigação que capturam outras formas de interrogar, as quais apenas fazem sentido quando localizadas, pois se tratam de singularidades. Quando uma pesquisa com povos tradicionais pergunta sobre o que é desenvolvimento para eles, indica a aclimatação de uma problemática que não necessariamente se apresenta como tal para certos repertórios e formas de viver (Chaparro, 2018). Essa estratégia de captura torna as práticas apontadas anteriormente como um "muro", pois se acaba por universalizar as estratégias de conhecimento, de maneira a considerar que apenas o eu as diferenciaria, em termos de individualidade, autoria e significados, mas mantendo como elemento imóvel a questão colocada. Dessa forma, abdica-se do espaço geográfico no qual acontecem essas práticas como espaço/vidas concretas que 
desafiam a própria forma de se conhecer e produzir conhecimento, bem como as problemáticas que se fazem ou não presentes em certas localidades ou tempos.

Em razão disso é que tanto os objetivos quanto o problema de pesquisa são dispositivos importantes para o exercício de interrogar a própria forma como a pesquisa se constitui, ou seja, qual o solo epistemológico e ético que a torna possível ao mesmo tempo que ela o faz possível. Dessa forma, as perguntas - de que modo, como, sob que condições, quais as articulações - permitem situar o problema de pesquisa, justamente, em um campo temático e problemático, no sentido de se interrogar como os fenômenos, fatos, empiricidades passam a se constituir como o que deve ser pensado e, especialmente, de que modos passa a ser pensado e se, sob certas condições, é possível pensá-lo: é possível perguntar sobre o modo como se produz uma boa mãe a partir de cuidados com a alimentação, exercícios físicos, cuidados com a beleza etc., para populações que não têm acesso à alimentação, moradia, educação? A problemática da boa mãe é uma problemática para essa população? Aí é que residem os efeitos de uma colonialidade e de um epistemicídio, por meio de deslocamentos de problemáticas e formas de abordá-las que não interrogam a si mesmas (Haberland, 2018).

Considerar, então, no processo de qualificação de um problema de pesquisa, os elementos conceituais e empíricos que lhe dão condições específicas de existência permite negociar com os universalismos dos próprios conceitos e os processos de naturalização de fenômenos sociais. Perguntar-se, tal qual fez Castel (1998), sobre a emergência da questão social, é se apoiar no que o autor analisa a respeito das diferentes formas como a pobreza se torna foco de estratégias de governo na Europa; porém perguntar-se sobre a emergência da questão social no Brasil é seguir outros rastros/conceitos, na medida em que os arranjos da questão social na Europa seguem percursos distintos dos arranjos da questão social no Brasil, já que neste a questão social está atravessada pelos efeitos da escravidão/colonização, e não sabemos de antemão se efetivamente podemos considerar a emergência de uma questão social no Brasil. Em ambos os casos, pode-se objetivar a análise de processos de exclusão social, porém a forma como acontecem e o que está em jogo, inclusive no modo de produção de conhecimento sobre essas realidades, indicam os riscos e perigos, mas também as necessidades.

Nossos conceitos que darão forma às interrogações - por exemplo, "De que modo uma política pública se articula à forma como as mídias sociais se ocupam da questão dos direitos humanos" - colocam em jogo distintas questões: a) que a questão dos direitos humanos está colocada para a mídia social; b) que os direitos humanos se situam no âmbito da política pública; c) que os direitos humanos são uma questão que deve ser pensada. O exercício é, de partida, considerar para quem os direitos humanos são uma problemática e com quais conceitos se articulam em um campo teórico que lhes dará certa densidade, ou seja, certa consistência para serem operacionalizados. Isso é situar o conceito no campo onde ele acontece. A partir disso, estranha-se o campo onde acontece para compreender se, ao ser deslocado, continua a ter a mesma consistência que anteriormente, ou se esta se modifica em novas combinações: ao situarmos a mídia social, é o conceito de direitos humanos que emerge? Ou são outros conceitos que acabam por assumir certo protagonismo, tornando-o um pouco mais opaco? 
Além disso, deve-se perguntar sobre a própria pergunta, se é a questão dos direitos humanos que estará em jogo nessa articulação. Portanto usar o conceito de direitos humanos como uma categoria de análise não permite que possa ser universalizado, de modo a evitar certas "imposições" de problemáticas a campos que lhe são estranhos. Nesse caso, as perguntas situadas anteriormente - com o que, como, onde e por que o campo dos direitos humanos se torna problemático - são fundamentais para fazer essa tensão e torção nos modos de pensar e montar um problema de pesquisa, bem como no que queremos produzir com nossa pesquisa em termos de objetivos.

Os objetivos e o problema de pesquisa fazem parte desse jogo, de certo epistemicídio, quando não consideramos as diferentes invisibilidades das singularidades, inclusive na forma de produção de conhecimentos que não habita uma zona de ausência de implicações. As finalidades de nossas pesquisas e as interrogações que permitem itinerários na pesquisa também são formas de anunciar o que conta e o que não conta nos modos de produção de conhecimento. É importante entender que as diferentes maneiras de composição do mundo, das realidades e das formas de habitá-las engendram distintos agenciamentos de pensamento, e que desconsiderá-las nas estratégias de investigação, colocando-as apenas no lugar de representações, mitos, folclores etc., é se afastar do caráter situado do próprio conhecimento. Isso não implica um relativismo da produção de conhecimento contra forma de absolutismo/universalismos, o que poderia abrir espaço para assegurar justificativas genocidas, de extermínios e violências. O que se considera com isso é que a produção de conhecimento é um campo de lutas por imposições de sentidos em termos de relações de poder. Não se trata, então, de relativizar o conhecimento, mas de considerar que diferentes processos de conhecer estão em jogo, por isso, trata-se de uma questão ética e política, na medida em que as afirmações que se fazem no mundo têm implicações concretas sobre os modos como se vive nesse mundo, e o que e quem, nessas formas, conta ou não.

Considerar a pesquisa de forma situada/localizada, a partir da experiência e de muros a serem transpostos, é uma estratégia para descolonização do pensamento e das trajetórias de pesquisa. Nesse caso, operar com uma noção espacial não é simplesmente definir o local de uma pesquisa e as características de perfil sociodemográfico, epidemiológico, sanitário etc. Assinalar os espaços/vidas concretos é se dobrar pelo plano que os constitui em termos de formas de viver e, com isso, de compreensão das estratégias de pensamento e governo que os organizam.

\section{Considerações Finais}

Conforme indicamos no início desta escrita, nosso foco era refletir sobre o modo como operamos com o problema e os objetivos de pesquisa. Esta discussão, apesar de não ser atual ou inédita, inscreve-se permanentemente no cotidiano acadêmico, na medida que significa um processo de produção. Neste texto, a ideia foi apontar a dimensão ética e política coextensiva do problema e objetivos da pesquisa, afirmando-se o caráter situado, portanto, de todos os movimentos que fazemos durante os processos de investigação.

Diante disso, indicaram-se alguns riscos e, ao mesmo tempo, anúncios do modo como pesquisamos, quando o ato de formular problema/objetivos é considerado de forma descolada de uma realidade que os torna possíveis. Além disso, intentamos situar elementos 
importantes nesse exercício de pensamento - formulação do problema e dos objetivos - a partir da experiência e dos muros a serem transpostos. A experiência e os muros a transpor se fazem no texto como estratégias para a afirmação da pesquisa como uma aposta ético-política e também como um modo de deixar de ser o que se é. Pesquisa, neste caso, por meio dos jogos que vão se constituindo no ato de pesquisar, em que o problema e os objetivos se fazem como instrumentos de interrogação não apenas do mundo, mas daquilo que consideramos afirmado nesse mundo, é um exercício de arriscar, de contestar e de inventar novas modalidades de compreender, de pensar e de viver.

\section{Financiamento}

Este artigo contou com o financiamento das agências de fomento à pesquisa CAPES e CNPq.

\section{Referências}

Bondía, J. L. (2002). Notas sobre a experiência e o saber de experiência. Revista Brasileira de Educação, 19, 20-28. Recuperado de http://www.scielo.br/pdf/rbedu/n19/n19a02.pdf Castel, R. (1998). Metamorfoses da questão social: Uma crônica do salário. Petrópolis: Vozes. Chaparro, Y. (2018). O mundo e o fim do mundo: Palavras de rezadores e guerreiros Avá Guarani sobre o desenvolvimento (Tese, Doutorado em Desenvolvimento Local, Universidade Católica Dom Bosco, MS, Brasil).

Deleuze, G., \& Foucault, M. (1972/1979). Os intelectuais e o poder. In M. Foucault, Microfísica do poder (pp. 69-78). (10a ed.). Rio de Janeiro: Edições Graal.

Foucault, M. (2003). Cómo nace un libro-experiencia. In M. Foucault, El yo minimalista y otras conversaciones (pp. 9-17). Buenos Aires: La Marca.

Foucault, M. (2018). O enigma da revolta. São Paulo: N-1 Edições.

Galison, P. \& Stump, D. J. (1996). The Disunity of Science - boundaries, contexts and power. Stanford University Press, Stanford-California.

Grosfoguel, R. (2016). A estrutura do conhecimento nas universidades ocidentalizadas: Racismo/sexismo epistêmico e os quatro genocídios/epistemicídios do longo século XVI. Revista Sociedade e Estado, 31(1), 25-49. doi:http://dx.doi.org/10.1590/ S0102-69922016000100003

Haberland, D. F. (2018). Manual da Boa mãe (Tese de Doutorado em Psicologia, Universidade Católica Dom Bosco, MS, Brasil).

Haraway, D. (1995). Saberes localizados: A questão da ciência para o feminismo e o privilégio da perspectiva parcial. Cadernos Pagu, (5), 07-41. Recuperado de https://periodicos.sbu. unicamp.br/ojs/index.php/cadpagu/article/view/1773

Kastrup, V (2007). A invenção de si e do mundo: Uma introdução do tempo e do coletivo no estudo da cognição. Belo Horizonte: Autêntica.

Löwy, I. (2008). Gênero e ciência. In J. A. Nunes \& R. Roque (Orgs.). Objectos impuros: Experiências em estudos sobre a Ciência (pp. 79-92). Portugal/Porto: Edições Afrontamento.

Machado, A. F. (2014). Filosofia africana para descolonizar olhares: Perspectivas para o ensino das relações étnico-raciais. Tear: Revista de Educação Ciência e Tecnologia, 3(1), 1-20. doi:https://doi.org/10.35819/\%23tear.v3i1.1854 
Mbembe, A. (2016). Necropolítica. Arte \& Ensaios, (32), 123-151. Recuperado de https:// revistas.ufrj.br/index.php/ae/article/view/8993

Rouse, J. (2007). Social practices and normativity. Philosophy of the Social Sciences, 37(1), 46-56. doi:https://doi.org/10.1177/0048393106296542

Stengers, I. (2000). As políticas da razão: Dimensão social e autonomia da ciência. Portugal: Edições 70.

Recebido em: 02/03/2020

Última revisão: 12/05/2020

Aceite final: 17/06/2020

\section{Sobre as autoras:}

Anita Guazzelli Bernardes: Doutora em Psicologia pela Pontifícia Universidade Católica do Rio Grande do Sul (PUCRS). Psicóloga. Docente e pesquisadora do Programa de Pós-Graduação em Psicologia da Universidade Católica Dom Bosco (UCDB), Campo Grande, MS. Brasil. E-mail: anitabernardes1909@gmail.com, Orcid: https://orcid.org/0000-0003-4742-6036

Neuza Maria de Fátima Guareschi: Doutora em Educação pela University of Winsconsin (EUA). Psicóloga. Professora adjunta do Programa de Pós-Graduação em Psicologia Social e Institucional do Instituto de Psicologia da Universidade Federal do Rio Grande do Sul (UFRGS), Porto Alegre, RS. Brasil. E-mail: nmguares@gmail.com, Orcid: https://orcid.org/0000-0001-5892-188X

Giovana Barbieri Galeano: Doutoranda em Psicologia Social e Institucional pela Universidade Federal do Rio Grande doSul (UFRGS), Porto Alegre, RS. Brasil. Psicóloga. E-mail: giovanagaleano@ hotmail.com, Orcid: https://orcid.org/0000-0002-5293-6439 